\title{
A Design Theory for IT supporting Online Communities
}

\author{
Paolo Spagnoletti \\ CeRSI-LUISS Guido Carli University \\ pspagnoletti@luiss.it \\ Andrea Resca \\ CeRSI-LUISS Guido Carli University \\ aresca@luiss.it
}

\begin{abstract}
Differently from other studies that tend to take into consideration actual behaviors of online community users, this paper addresses the design problem of IT platforms for supporting these communities. At the basis of this design theory here introduced there is the so called kernel theory. The comparison between offline and online communities allowed to outline main factors of this theory that were used in order to derive prescriptions for the metarequirements, the product features (meta-design), the design process (design method) and the definition of testable design product and process hypotheses. An intelligent multimedia platform providing innovative social e-services for European elderly persons and their social entourage constituted the case study in which the IT design theory was applied.
\end{abstract}

\section{Introduction}

In the last decade, the online community phenomenon has attracted much attention from several fields of studies [11]. The relevance of this topic in management and information systems studies can be motivated by the potential impact of online communities on the value proposition to customers and to the overall business model. Communities are in fact considered since long time a desirable feature of online business strategy [9][2][15]. By enabling the development of online communities, firms can foster their relationships with customers, reinforce brand recognition, use customer feedback to develop products and services more effectively, accumulate customer information, improve pre and post transaction services and test new products. In essence, a business supported online community is an effective tool for Customer Relationship Management (CRM) [18][31][39][27][6]. Similar models for innovating customer relationships are recently promoted also in the public sector where new e-Government paradigms such as open government and open participation are based on the development and management of online communities. In this case the goals are openness and transparency [22]. 
Since IT plays a key role in enabling the development and sustainability of online communities, specific capabilities are requested to introduce this form of innovation. In fact, internal IT staffers and also external consultants and practitioners must be aware of the specific requirements which underpin IT artifacts supporting online communities together with the principles for managing them. These capabilities are also useful for customer relationship managers who are obliged to change their ways for interacting with customers and exploit the potential of the new tools [2][14].

According with Koh et al. [14], realizing sustainable online communities depends on the ability to develop and maintain communities in which individuals have both the opportunity and the motivation to participate and contribute. Moreover, IT systems features available to online community members must be appropriate to the task at hand and must satisfy their needs in terms of ease of use [16]. Therefore the community supporting platform is a critical success factor for community building as well as economic and social aspects. A successful platform is the one providing those services to the community, which enable a rich and appropriate communication and social interaction [30].

Although the available body of knowledge on online communities contributes in explaining and sometimes predicting online community dynamics, there remains little understanding of how IT systems supporting such communities should be developed and maintained [31]. In fact, several studies on online communities concentrates on the analysis of huge amounts of data collected through IT systems supporting social interactions. These studies have demonstrated that virtual communities are sustainable only when they provide benefits that surpass the costs of membership. Furthermore, sustainability is related to members' attraction/retention which depend on membership size and communication activities (i.e. post, view) [4][14]. In this proposal, the value of an online community increases quadratically with the number of participants and since participation in online communities is voluntary based, the main purpose in this context is to ensure the sustainability of a community.

The availability of raw data on community members' behavior has been a driver for conducting these studies allowing researchers to easily perform statistics and other analysis (i.e. social network analysis). For instance, new online marketing research techniques have been proposed for providing consumer insight [15]. However, this kind of data offers a partial view on a complex phenomenon by focusing on the actual behavior of users but without taking into account other aspects such as the properties of IT systems supporting the social interaction. As an example, some authors maintain that "sociability" other than usability is a design criteria to ensure that technology can support social interaction [24]. Furthermore, a few studies concentrates on the development process for this type of IT systems through case studies [16][31].

Our objective is to contribute to this body of knowledge by the means of a longitudinal study focused on the development process of an IT platform supporting online communities. This approach allows to investigate the link between IT design choices and online community behaviors. The final goal of this paper is to develop a theory for design and action which is specifically tailored to IT supporting online communities (ITsOC). In other words, we 
aim to give explicit prescriptions on how to design and develop applications and practices supporting social interaction among members of an online community.

The empirical part of this work is based on the analysis of the development process of a networking platform $\left(\right.$ HOPES $\left.^{1}\right)$ which supports social interaction of elderly people with relatives and caregivers. This platform is under development in the context of a European project. We refer to this case for performing a first round of evaluation of the proposed design theory. The preliminary feedbacks of experts, practitioners and users involved in the HOPES project are discussed to present the lessons learned so far.

The paper is structured as follows. We firstly describe the process through which we formulate the design theory for ITsOC. Then we introduce theories underpinning our understanding of offline and online communities. After that we introduce our design theory by presenting the HOPES case and by discussing the main findings at this stage of the project. Finally we close the paper with implications for research and practice.

\section{The design theory framework}

The vast amount of research contribution on online communities, lies on different theories such as RBV [4], systems-theory [12], gift theory [31][37], etc. With respect to Gregor's framework for classifying theories in Information Systems [8], research on online communities has mainly contributed to the development of theories for analyzing [30], theories for explaining [12], theories for predicting [27], theories for explaining and predicting [2]. In fact, a few studies belong to the theories for design and action whose focus is on "how to do something". Such theories give explicit prescriptions on how to design and develop an artifact, whether it is a technological product or a managerial intervention [8]. An example of theory in this domain has been provided by Preece who advocates an iterative community-centered development approach to web site design because communities and their needs evolve over time, and web site design must in turn evolve [16][25].

The problem of giving explicit prescriptions on how to design and develop an IT system supporting social interaction among members of an online community belongs to what has been named as "IS design theory" by Walls et al. in their seminal work [34] inspired by Simon's [29] and Dubin's [5] contributions. In this article and in the following review and assessment in 2004 [35], Walls et al. distinguish two aspects of a design theory: the design product and the design process. The design product is composed by meta-requirements, meta-design (features), kernel theories and a set of testable design product hypothesis. Differently, the design process components are the design method, kernel theories and a set of testable design process hypothesis. 


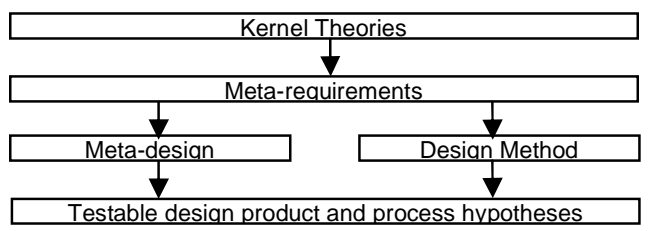

Figure 1. Theory components (Adapted from [35])

This model has been extended by Gregor and Jones [7] who have proposed a new "anatomical skeleton" for IS design theories, based on eight components which encompasses four issues identified in the Walls et al. conceptualization. For instance, the distinction between kernel theories for design processes and kernel theories for design products made by Walls et al. [35] has been criticized. For the purposes of the present work, we derive a model for formulating a design theory of ITsOC that lies on both the above mentioned frameworks. The model is based on five components whose relationships are depicted in figure 1.

As a first step towards the definition of a design theory for ITsOC, we need to clearly identify the purpose and scope of the theory. This will help us in motivating the choice of kernel theories and to further derive prescriptions for the meta-requirements, the product features (meta-design) and the design process (design method) as well as the definition of testable design product and process hypotheses.

\section{Offline and online communities}

The purpose of a kernel theory for building an ITsOC design theory is to explain the behavior of community members of online communities in opposition to offline ones. In fact, the design problem of ITsOC lies on the need for specific requirements, architectures, and design methods envisaging IT systems for supporting online communities.

\subsection{Sociological views on communities}

To study communities poses a traditional question of the sociological investigation. Is a community composed by a collection of individuals who actively forge it interacting with each other? Or does it acquire an autonomous identity able to determine the activities of their members? In both cases, community is seen as a whole of organized relationships established among its members. However, the first argument maintains that at the basis of a community there are individual actions and these actions determine the nature of relationships. Differently, the second argument stresses the fact that a community is an entity, a system of relationships able to give shape to the

\footnotetext{
1 This article has been drafted in the context of the HOPES project "Help and social interaction for elderly On a multimedia Platform with ESocial best practices" funded by the EU Commission under the AAL Programme. We thank all the project partners for their contribution. Project website: http://www.hopes-project.org
} 
activities of the members. In this dichotomy (respectively agency/structure), a social phenomenon such as a community can be examined both as the result of the actions of singular individuals that establish specific relationships (agency) and as the result of a system of relationships that conditions their members (structure) [36]. Both these perspectives will be taken into examination in order to examine a community. The objectivist perspective (structure) prevails in Tonnies's study [32]. What is a community? Tonnies sets it against society. Society represents a phenomenon in which individuals interact among each other because they need it but without any will. They follow their own interest and are separated despite factors that keep them related to each other. On the other hand, communities represent a substantially different phenomenon as unifying factors prevail. Unifying factors that are based on relationships characterized by closeness and gratitude. Jargons are shared as habits, spaces, memories and common experiences. Communities are seen as an organic totality in which existing relationships are typified by feelings of togetherness and mutual bonds. Modernity and the individualization processes that societies are experiencing in the last decades put into question the value of the concept of community as it has been outlined by Tonnies. In this respect, it is considered outdated and unable to describe social phenomena that, in any case, have reference to community. More recent works in this field tend to abandon the objectivist stance (structure) in favor of the subjectivist one (agency). Particularly, Nancy [19] maintains that the distinction between community and society is no more helpful. Nowadays, the point is to acknowledge the limits of communitarian relationships and the attempt is to humanize social interactions. In this context, a community can only be seen as the sharing of only some parts of individual existence.

\subsection{Economical views on communities}

The community phenomenon has not only been studied by sociologists but also by economists. Economists who follow as well the subjectivist perspective (agency). Olson's work, "The logic of collective action" [19], is seen as a landmark in this respect. The argument supported is that rational and self-interest individuals do not act to achieve their common or group interest as self-interest prevails against common interest. The free-riding phenomenon is strictly related to this assumption. That is, if there is the possibility not to be excluded by public goods, individuals are not inclined to voluntary participate to their production but they will take advantage of others' activity without supporting any cost. The presence of an external authority, that supervises collaborative behaviors and provides selective incentives that reward givers and penalize free riders, is seen as a solution in this respect leading to the production of public goods [19]. But this is not the only solution. The subdivision of public goods among group members assigning property rights to each of them is a further one. The passage from public goods to private goods avoids opportunistic behaviors [1]. Ostrom investigates these solutions suggesting that both the introduction of an external authority and the privatization of public goods are not optimal [21][22]. On the basis of empirical studies, it emerges that communities, autonomously and spontaneously, can envisage collective actions able to regulate and manage public goods excluding free riders from taking advantage of them. What are the factors that determine this 
situation? Several main principles were identified [21]: a) members and non-members of the community have to be clearly separated (boundary rules); b) rules adopted have to take into consideration local circumstances whereas a central authority tends to standardize different situations; c) benefits derived from the use of public goods have to be equally distributed according to a specific regulation; d) members are entitled to participate actively in the decision making process related to the government of the community; e) the necessity of a supervisor, acknowledged by the community, able to sanction behaviors out of line with the regulation; f) the presence of effective and efficient mechanisms for dispute-resolution that prevent to undermine trust among members due to lasting conflicts; g) a central authority recognizes members' self-regulation in order to envisage and impose new rules; $h$ ) in case of public goods of large entity, a multi-level governance is recommended where small local committees, ruled by specific regulations, mutually cooperate.

\subsection{Online communities}

In the previous paragraph, the tentative attempt to study communities is based on the assumption that only faceto-face relationships constitute the raw material of these entities. Nevertheless, the development of ICT (information and communication technology) has allowed the proliferation of modalities by which interpersonal relationships can be mediate both through synchronous (phone, chat etc.) and asynchronous means. ICT is conceived of as the nervous system through which mediated interactions develop representing new possibilities to establish both social and economic relationships. The questions are if this new kind of relationships leads to also to a different kind of communities and if concepts and theories developed for investigating traditional communities are still valid in order to study these new phenomena. Concerning the first question, the debate is still under way. In this proposal, also terminology is uncertain. In 1993, Rheingold (1993) introduced the term virtual community in order to define social aggregations that emerge from the internet when several individuals are involved in a public discussion for a considerable period of time [26]. In 2000, the term online community came to the fore. Actually, the intention was to classify the rituals and stages of online community interaction resulting in the so called membership life cycle [13]. Both these perspectives tend to consider social relations settled in the cyberspace as something different in respect to traditional ones. On the other hand, according to Wellman, online and offline communities are coexistent [38]. Offline and online are continuously more overlapped and new social environments come out where individuals become members of several social networks of both types.

On the basis of Tonnies's view (structure), Pravettoni considers a series of factors at the basis both of offline and online communities and specifically: the concept of space; the tie strength; the rule system; the community structure and the role of its members; participants' identity [32][23]. A shared space in which individuals interact is at the basis of offline communities. In the case of online communities, this space is present as well. However, its nature is completely different. Geographical terms lose importance in favor of a so called cyberspace where the sense of belonging is not related to the place of origin of individuals but to the possibility to have access to the internet.The 
strength of ties among members of an offline community is given. In contrast, in online communities, it is the result of individuals' free will. This means that weak ties prevail in the latter, even though it cannot be excluded otherwise, leading also to large communities. Offline communities, on the other hand, are necessarily small preventing the possibility to interweave connections with a wide range of actors. Both online and offline communities require tacit and explicit rules. Tacit rules as members are subject to a socialization process in order to acquire shared values and an etiquette able to build a favorable environment for interacting. However, especially in online communities in which participants are more heterogeneous, tacit rules are not sufficient and explicit ones become necessary. Offline communities tend to be characterized by a clear role structure. Each member has a specific position that is recognized by others. Online communities are not like this. The structure is more flexible and according to the level of involvement member can modify their own status. Nevertheless, leadership roles persist also in this case even though they are in charge mainly of preserving norms and values through coordination and a monitoring activity. A substantial anonymity characterizes relationships in online communities. Members can build their own identities that can be close or not to the real ones. Age, sex, race, nationality, economic conditions etc. are not evident and they can be concealed favoring the development of relationships. Circumspection and prudence that typify interactions in offline community are overcome supporting spontaneity and sincerity. At the same time, dissimulations and concealments are also possible as relationships are essentially based on language as facial expressiveness, glances or gestures do not characterize these relationships.

The following table summarizes features that characterize offline and online community according to the five factors above mentioned. 
Table 1. Main characteristics of offline and online communities (see [23])

\begin{tabular}{|l|l|l|}
\hline & Offline community & Online Community \\
\hline $\begin{array}{l}\text { The concept } \\
\text { of space }\end{array}$ & $\begin{array}{l}\text { A shared space and physical proximity } \\
\text { are at the basis of offline communities }\end{array}$ & $\begin{array}{l}\text { The space (cyberspace - who has access to the internet) has } \\
\text { not a geographical connotation and the sense of belonging is } \\
\text { not related to the place of origin of individuals }\end{array}$ \\
\hline $\begin{array}{l}\text { The tie } \\
\text { strength }\end{array}$ & $\begin{array}{l}\text { Strong ties prevail as based on family } \\
\text { and friend relationships. Communities } \\
\text { are small }\end{array}$ & $\begin{array}{l}\text { Weak ties prevail and it is possible to establish relationships } \\
\text { with a large range of actors. Communities can also be large. }\end{array}$ \\
\hline system & $\begin{array}{l}\text { Tacit rules predominate due to } \\
\text { members' socialization process in } \\
\text { which specific values are instilled }\end{array}$ & $\begin{array}{l}\text { Both tacit and explicit rules are required and they can be } \\
\text { strict as members tend to be heterogeneous }\end{array}$ \\
\hline $\begin{array}{l}\text { Community } \\
\text { structure }\end{array}$ & $\begin{array}{l}\text { Roles are clearly established and can } \\
\text { be organized hierarchically. Members' } \\
\text { status is important. }\end{array}$ & $\begin{array}{l}\text { Roles are clearly established but the structure is more } \\
\text { flexible. Members, according to their involvement, can } \\
\text { modify their status }\end{array}$ \\
\hline $\begin{array}{l}\text { Participants' } \\
\text { identity }\end{array}$ & $\begin{array}{l}\text { Identity is manifest. Each member is } \\
\text { recognized by others and his/her } \\
\text { background influences the nature of } \\
\text { relationships }\end{array}$ & $\begin{array}{l}\text { A substantial anonymity prevails. Identities can be close or } \\
\text { not to real ones so that sincerity and spontaneity are } \\
\text { favoured. Dissimulations and concealments are not excluded }\end{array}$ \\
\hline
\end{tabular}

\section{The ITsOC Design Theory and the "HOPES" case}

HOPES is an intelligent multimedia platform providing innovative social e-services for European elderly persons and their social entourage (as carers/supporters and IT tutors when needed). It is under development in the context of a European project started in September 2010, with the first prototype delivered in June 2011. The ultimate goal of the project is to enhance socialization, quality of life and autonomy of elderly persons by preventing isolation and loneliness, and generating positive social experiences and behavior. In few words, the European project proposes to foster social interactions through the development of an accessible, easy-to-use and innovative IT platform to provide a forum of well aging, an exchange of "social best practices" and socialization services in a European network. The general requirements at the basis of the project proposal demand for the integration of a range of ITbased solutions for: 1) managing existing e-information by exhaustive search of available information (Web and databases crawling) and intelligent structuring (i.e. TextMining) in the HOPES repository; 2) transforming selected information into personalized solutions; 3) providing validated solutions as "e-Social Best Practices" (SBP). All these services must be provided through a Web 2.0 approach by supporting the social interaction of end users. These characteristics make the HOPES platform an instantiation of what we have defined as ITsOC so that it does not only provide usable services to some particular classes of end users (i.e. elderly people, care givers, etc.) but also supports 
their social interaction. Furthermore, the sustainability of the online community supported by the HOPES platform represents a fundamental part of the business model. Therefore, all the properties that have been illustrated referring to ITsOC apply in the HOPES case and this makes this platform a suitable candidate for validating our design theory.

We start from the structure of our kernel theory on online communities in order to formulate the remaining design theory components. For each of the five characteristics of online communities which have been summarized in table 1, we derive the meta-requirements (MR), the meta-design (MD), the design methods (DM) and the testable hypotheses (TH). Thereafter, we instantiate these results through evidences emerging from the HOPES case and this is done by describing the corresponding HOPES requirements (R), design choices (D), requirement analysis methods (M), and evaluation items (E). In other words, for brevity, we will describe the design theory elements and the instantiation of these elements in the HOPES case together in the sections below. As far as the methodological assumption concerns, the empirical evidence drawn on the case can provide support to the more general problem of conceptualizing a design theory for ITsOC.

Table 2. The Design Theory for ITsOC

\begin{tabular}{|l|l|l|l|l|l|}
\hline & The concept of space & The tie strength & The rule system & Community structure & Participants' identity \\
\hline MR & $\begin{array}{l}\text { ubiquitous access, } \\
\text { interoperability }\end{array}$ & $\begin{array}{l}\text { sociability and } \\
\text { interoperability }\end{array}$ & personalized contents & security & privacy \\
\hline MD & $\begin{array}{l}\text { sw architecture, } \\
\text { multilinguism, } \\
\text { personalized interfaces }\end{array}$ & $\begin{array}{l}\text { features for } \\
\text { information } \\
\text { exchange }\end{array}$ & $\begin{array}{l}\text { dynamic adaptation of } \\
\text { contents to user profiles }\end{array}$ & $\begin{array}{l}\text { policies and modules } \\
\text { for managing } \\
\text { authorizations }\end{array}$ & $\begin{array}{l}\text { authentication } \\
\text { module and rules for } \\
\text { authentication }\end{array}$ \\
\hline DM & $\begin{array}{l}\text { "personas" definition } \\
\text { through focus groups }\end{array}$ & $\begin{array}{l}\text { iterative } \\
\text { development }\end{array}$ & $\begin{array}{l}\text { contribution of domain } \\
\text { experts }\end{array}$ & $\begin{array}{l}\text { risk management } \\
\text { methods }\end{array}$ & $\begin{array}{l}\text { analysis of privacy } \\
\text { regulation }\end{array}$ \\
\hline TH & $\begin{array}{l}\text { Ergonomy of the } \\
\text { platform, coverage of } \\
\text { the users' classification }\end{array}$ & $\begin{array}{l}\text { actual use and } \\
\text { coverage of users' } \\
\text { needs }\end{array}$ & $\begin{array}{l}\text { relevance of the contents; } \\
\text { actual application of } \\
\text { explicit rules }\end{array}$ & $\begin{array}{l}\text { trade-off between } \\
\text { security and usability }\end{array}$ & privacy perception \\
\hline
\end{tabular}

\subsection{The concept of space}

Since the space has not a geographical connotation, community members should be able to access the platform anywhere, anyhow and anytime according with the specific services provided. The idea is to design a space that is friendly, in which users find elements that can be easily recognized so that it is possible to be proactive and then exercise participation actively. This theoretical principle translates into the meta-requirements of ubiquitous access and device interoperability (MR). In the HOPES case, the platform must be accessible through any device available 
to each category of users. For instance, it is required that elderly people have access to the platform through any devices available in their home (i.e. smartboxes). On the other hand, care-givers can have access to these services both from personal computers and other devices (i.e. smartphones) (R).

The meta-design choices related to the above mentioned meta-requirements are related to the level of centralization of the system architecture and to the features that allow users to access the appropriate multimedia material independently from language (MD). Within the HOPES case, these meta-design elements are instantiated with the choice of having a centralized repository for multimedia contents and a personalized interface ensuring access from a wide range of devices for the different classes of users. In addition, auto-translation functionalities have been implemented in order to allow users to consume contents (i.e. articles, comments) (D).

Design methods deriving from the meta-requirements are related to the ways in which the requirement analysis is performed. Since ITsOC do not involve a predefined number of users, it is important to identify the categories of members who take part to the online community. This can be done through the organization of focus groups with possible representatives of the community members and then through the validation of the derived categories of users by discussing with domain experts (DM). In the HOPES case, at least one focus group has been organized in each country involved in the project and then the results have been described with a common template. A meeting with domain experts has been organized in order to merge the outcomes of the previous phase and to agree on a restricted set of categories (three "personas") which is independent from the geographical location (M). The testable design product hypotheses of ITsOC design theory are related to the ergonomy (i.e. usability, accessibility, and safety) of the platform for the different categories of community members. Differently, the design process testable hypotheses are related to the level of coverage of the different needs identified through the requirement analysis (TH). In the HOPES case, these hypotheses correspond to checking if elderly people and informal/formal caregivers can both access the platform while performing their daily activities and if online community members belongs to one of the three categories of personas identified $(\mathrm{E})$.

\subsection{The tie strength}

According with our kernel theory, weak ties prevail in online communities and it is possible to establish relationships with a large range of actors. Nonetheless, information exchange should be favored as the possibility to join other users. Interests, curiosities and needs should be easily detectable in order to establish new ties. All of this can be translated into the meta-requirement of sociability and interoperability among applications (MR). In the HOPES case, the requirement of supporting social relations, social links, socialization, and active participation to a community for elderly people represent the instantiation of the sociability meta-requirement. On the other hand, interoperability refers to the non functional requirement of satisfying those requirements independently from the devices and applications of other community members (R). 
From a meta-design standpoint, ITsOC provide features which make users involved in both providing information and being informed by other users (MD). In the HOPES case, these features are grouped in three sets: 1) networking features enabling elderly people to share information and experiences with others; 2) management of temporality to properly plan daily activities; 3 ) certified solutions to every-day problems by and for end-users (D).

The design method is based on the collection of users' needs through focus groups and an iterative process to develop and evaluate the features implemented (DM). In the HOPES case, all these steps have been performed involving representatives of the different end users categories (M).

Finally, the actual use of implemented features and the coverage of users' needs must be questioned (TH) as testable design product and process hypotheses for the ITsOC design theory. In the HOPES case, this has been done by observing the frequency of use of different functions and by measuring the strengthens of ties among online community members (E).

\subsection{The rule system}

Our kernel theory suggests that in online communities both tacit and explicit rules are required and they can be strict as members tend to be heterogeneous. Further, a sort of supervision should be provided by the system itself allowing or not allowing specific operations in order to prevent any misbehavior. This translates into the metarequirement of providing personalized contents (MR). In the HOPES case, tacit rules have been translated into the requirement of providing personalized contents according with the preferences of every single user. As far as explicit rules concerns, they have been translated into the requirements of providing appropriate contents to the users by respecting medical and social constraints $(\mathrm{R})$.

From the meta-design standpoint, it is required the presence of some components providing the capability to dynamically adapt the contents to the user profile (MD). In the HOPES case, some semantic functionalities have been implemented to provide personalized contents through semantic similarity reasoning and routing (D).

The contribution of domain experts is extremely important in this phase of the design method for ITsOC (DM). In the HOPES's case, this role has been played by physicians and other professional caregivers who have validated the outcome of semiautomatic tools adopted for building the ontology (M).

The testable hypotheses of our ITsOC design theory are related, here, to the interest of users in the contents provided by the platform and to the level of precision in the application of explicit rules (TH). In the case under examination, the evaluation items related to the tacit rule system are based on the actual consumption of contents provided to elderly users. In contrast, those related to the explicit rule system refers to the reliability of semantic search results when they apply rules to content selection $(\mathrm{E})$.

\subsection{Community structure}


The roles within an online community should be clearly established while its structure should be characterized by flexibility and members have the opportunity to modify their status according to their involvement. In this respect, the envisaged platform should support information related to the role system and, at the same time, provide the possibility to elderly to become caregivers, to caregivers to become neighbors, to neighbors to become care givers etc. These characteristics are linked to security as meta-requirement of the ITsOC platform (MR). In HOPES, non functional requirements addressing security issues have been considered from the beginning of the project. In fact, the underestimation of these aspects can compromise even the safety of elderly members due to the possible provision of unsafe contents $(\mathrm{R})$.

From the meta-design standpoint, this requirement implies appropriate modules for managing authorizations and a policy to deal with accounts (MD). In the HOPES case, only a restricted number of trustable users have the permission to change users' roles. On the other hand, every user is allowed to invite new members to join the community as basic users (D).

Here, the design method should be based on the application of risk management methods involving domain experts in brainstorming sessions (DM). As far as HOPES case concerns, physicians have identified main risks and agreed the administration policy of the platform with e-care service providers (M).

The testable hypotheses with respect to the community structure dimension are mainly related to the trade-off between security and usability of the system functions (TH). This has been translated into two questionnaires in the HOPES platform. The first was addressed to elderly people to evaluate their trust in the HOPES contents. The second targeted caregivers in order to evaluate their perception on the usability of administrative functions (E).

\subsection{Participants' identity}

The last characteristic of an online community is that a substantial anonymity prevails among members. In fact, identities can be close or not to real ones so that sincerity and spontaneity are favored but dissimulations and concealments are not excluded. This theoretical statement is directly linked to the privacy meta-requirement. This means that the possibility to reveal a partial identity should be provided to the basic members of the community (MR). In the HOPES case, this requirement was adopted for elderly users and for their relatives. Differently, professional caregivers should identify themselves through different mechanisms (R).

In terms of meta-design, the authentication module together with the rules for authentication should be defined (MD). This has been implemented in the HOPES case through a federated authentication infrastructure and a single sign on feature which allows to access the platform once the user has been authenticated through one of the most common social networks (i.e. Facebook, Google, etc.). A federated repository of professional caregivers allows to implement a different authorization mechanism for this class of users (D).

In order to face these design issues, it is important to analyze the privacy regulation and to carefully check the compliance of the technical and administrative solutions (DM). This has been done in the HOPES case with a 
particular reference to the privacy regulation within the four countries involved in the project. The choice to delegate the identification and authentication process for basic users to external systems is the result of a discussion among project partners on the constraints of managing end users' personal details (M).

The testable hypotheses in this domain are related to the privacy perception of end users (TH). In the case of HOPES, it was evaluated through questionnaires among elderly people and their informal caregivers using the platform (E).

\section{Discussion}

The adopted research approach shares the same underpinning principle of the design science paradigm as described by Hevner et al. [10]. According with these authors, a research contribution falls under the design science paradigm when the knowledge and understanding of a design problem and its solution are acquired in the building and application of an artifact (i.e. construct, model, method, instantiation). Moreover, the design science paradigm focuses on both creating and evaluating innovative IT artifacts that enable organizations to address important information-related tasks. Hence, a thorough demonstration of utility, quality and efficiency of the artifact must be carried out through the application of rigorous evaluation methods.

In our case the development of the HOPES platform (instantiation) is informing the definition of a design theory for ITsOC. Therefore the validity of the theory is closely related to the evaluation of the HOPES platform. However, evidences collected during the first year allow us to better illustrate only the intermediate results which are summarized in Table 2. Particularly, we are not in the realm of the so called summative evaluation but in the formative evaluation one [28]. In other words, this evaluation is targeted to the project improvement involving both internal and external evaluators rather than to its final result. In this proposal, some considerations are based on the fact that only the HOPES first platform prototype has been developed and the first round of user evaluation is scheduled at the end of 2011. At this point, descriptive evaluations become available using, for instance, information from the knowledge base (e.g. relevant research on online communities). Evaluations are related to the artifact's utility and to scenarios that render it possible.

With these premises, for brevity reasons we illustrate here a couple of testable hypotheses providing examples of relationships between the elements listed in Table 2. Such testable hypotheses can be further investigated to demonstrate both the effectiveness of the new artifact (ITsOC) and the appropriateness of the adopted development process. These propositions are truth statements about the design theory coherently with the adopted design research framework. Each proposition is followed by a short description that demonstrate how feedbacks collected from practitioners, experts and users in the HOPES case confirm the hypothesis.

Proposition 1: effective ITsOC, with respect to the space dimension, must be highly interoperable platforms at the technical and semantic level. 
From technical meetings with domain experts and IT practitioners, interoperability has emerged as an important issue in the HOPES case. In fact, elders do not use the same devices as their relatives and their professional caregivers. Elders are more familiar with traditional cognitive devices such as mobile phones and TV sets while caregivers can use smartphones and personal computers. This implies that technical interoperability must be ensured by the sw platform through the use of open standards and service oriented architectures. Furthermore, semantic interoperability translates into multilinguism requirements and functionalities to make available knowledge embedded in the online community to all members independently from their geographical location and language skills. In the HOPES case this knowledge is represented by social best practices such as, for instance, "The (good) management of administrative documents at home". Usability, accessibility and safety metrics, together with geographical distribution of users will be used in the prosecution of the project to assess the effectiveness of the ITsOC solution.

Proposition 2: the application of the "personas" method to identify user categories leads to the development of highly interoperable ITsOC at both technical and semantic level.

Developing a platform supporting online communities it is impossible to identify users' characteristics in advance such as their technical and language skills. In the HOPES project the definition of general user categories applicable in the four countries has been performed by collecting data in five separate focus groups (one for each pilot site) and then by discussing the profiles of different "personas" during a series of technical meetings. At the end of this process, eight user categories have emerged, two for elderly and six for caregivers. Even though these categories must be validated in the next phases of the project, they have provided a first useful information for deriving interoperability requirements at both technical and semantic level.

\section{Conclusions}

In this paper, we presented a design theory of IT platforms supporting online communities. The final goal of this contribution is to address the sustainability issue of online communities through the design of an appropriate ITsOC. A kernel theory related to the characteristics of an online community led to a set of meta-requirements, metadesigns, design-methods, and testable hypotheses.

A rigorous evaluation of the derived prescriptive design theory of ITsOC is out of the scope of the present paper and it would require the thorough adoption of appropriate methods which can be either observational, analytical, experimental, test based, or descriptive. Nevertheless our contribution is threefold. First we have justified the need for a design theory for ITsOC. Second we have identified the theoretical foundations of a proposed design theory in the dichotomies from sociological and economic views on online communities. Finally we have derived the theory components and a set of propositions that will guide further research to assess the theory.

\section{References}


[1] Alchian, A.A. and H. Demsetz, Production, Information Costs, and Economic Organization. The American Economic Review, 62(5), p. 777-795, 1972.

[2] Balasubramanian S. and Mahajan V., "The Economic Leverage of the Virtual Community," International Journal of Electronic Commerce, 2001, 5(3), pp. 103-138

[3] Bertota J.C., Jaegera P.T. and Grimes J.M., Using ICTs to create a culture of transparency: E-government and social media as openness and anti-corruption tools for societies, Government Information Quarterly, Volume 27, Issue 3, July 2010, Pages 264-271

[4] Butler, B., Membership size, communication activity, and sustainability: The internal dynamics of networked social structures. Information Systems Research 12, 4, 346-362, 2001

[5] Dubin, R., Theory Building, revised edition, London: Free Press, 1978

[6] Friesen, G.B. Redefining B2C: From "business to consumer" to "building toward community." Consulting to Management, 15, 1 (March 2004), 21-26.

[7] Gregor S. and Jones D., The Anatomy of a Design Theory. JAIS vol. 8, Issue 5, Art 2, 2007

[8] Gregor, S., The Nature of Theory in Information Systems, MIS Quarterly, (3)30, pp. 611-642, 2006

[9] Hagel, J.I. and A. Armstrong, Net Gain: Expanding Markets Through Virtual Communities, Cambridge: Harvard Business School Press, 1997

[10] Hevner, A.R, March S.T., Park J. and Ram S., Design Science in Information Systems Research” MIS Quarterly, 28 (1): pp. 75-105, 2004

[11] Honglei, Virtual Community Studies: A Literature Review, Synthesis and Research Agenda, Proceedings of the Americas Conference on Information Systems, New York, New York, August 2004

[12] Jones, Q. \& Rafaeli, S., “Time to Split, Virtually: 'Discourse Architecture' and 'Community Building' Create Vibrant Virtual Publics,” Electronic Markets, 2000, 10(4), pp. 214-223

[13] Kim, A.J., Community Building on the Web: Secret Strategies for Successful Online Communities, Berkeley: Peachpit Press, 2000.

[14] Koh J., Kim YG, Butler B, and Bock GW, Encouraging participation in virtual communities. Communications of the ACM, Vol. 50, No. 2, 2007

[15] Kozinets, R.V., The Field Behind the Screen: Using Netnography for Marketing Research in Online Communities. Journal of Marketing Research, 2002. 39(1): p. 61-72.

[16] Macaulay L. A., Keeling K., McGoldrick P., Dafoulas G., Kalaitzakis E., and Keeling D., "Co-evolving E-tail and On-Line Communities: Conceptual Framework”, International Journal of Electronic Commerce / Summer 2007, Vol. 11, No. 4, pp. 5377.

[17] Markus M.L., Majchrzak A. and Gasser L., A design theory for systems that support emergent knowledge processes. MIS Quarterly, Vol. 6, No. 3, pp. 172-212, 2002

[18] McWilliam, G., Buidling Stronger Brands Through Online Communities. Sloan Management Review, 41(3): p. 43-54, 2000

[19] Nancy, J.-L., The Inoperative Community, Minneapolis, MN: University of Minnesota Press, 1991.

[20] Olson, M., The logic of collective action: public goods and the theory of groups, Cambridge: Harvard University Press, 1971. 
[21] Ostrom, E., Collective Action and the Evolution of Social Norms. The Journal of Economic Perspectives, 14(3), p.137-158 2000.

[22] Ostrom, E., Governing the commons: the evolution of institutions for collective action, Cambridge: Cambridge University Press, 1990.

[23] Pravettoni, G., Web Psycology, Milano: Guerini e Associati, 2002.

[24] Preece, J. Sociability and usability in online communities: Determining and measuring success. Behavior \& Information Technology, 20, 5 (September 2001), 347-357.

[25] Preece, J. Supporting community and building social capital. Commun. ACM 45, 4, 37-39. 2002

[26] Rheingold, H., The virtual community: homesteading on the electronic frontier, Reading: Addison-Wesley, 1993.

[27] Rothaermel, F. and Sugiyama, S. Virtual Internet communities and commercial success: Individual and community-level theory grounded in the atypical case of TimeZone.com. Journal of Management 27, 3 (Aug. 2001), 297-312.

[28] Scriven, M. Evaluation Thesaurus. Newbury Park, CA: Sage Publications, 1991

[29] Simon, H., The Sciences of the Artificial, 3rd edition, Cambridge, MA: MIT Press, 1996

[30] Stanoevska-Slabeva K., Schmid B.F., A Typology of Online Communities and Community Supporting Platforms, Proceedings of the 34th Hawaii International Conference on System Sciences - 2001

[31] Stockdale R. and Borovicka M., Developing an Online Business Community: A Travel Industry Case Study, Proceedings of the 39th Hawaii International Conference on System Sciences, 2006

[32] Tonnies, F., Community and association: (Gemeinschaft und gesellschaft), London: Routledge \& Kegan Paul, 1955.

[33] Van Aken, J., Management Research Based on the Paradigm of the Design Sciences: The Quest for Field-tested and Grounded Technological Rules, Journal of Management Studies, (41)2, pp. 219-246, 2004

[34] Walls, J. G., G. R. Widmeyer, and O. A. El Sawy, "Building an Information System Design theory for Vigilant EIS, Information Systems Research, (3)1, pp. 36-59, 1992

[35] Walls, J. G., G. R. Widmeyer, and O. A. El Sawy, Assessing Information System Design Theory in Perspective: How Useful Was Our 1992 Rendition?, Journal of Information Technology Theory and Practice, (6)2, pp. 43-58, 2004

[36] Walsh, D.F., Structure/Agency. In C. Jenks, cur. Core sociological dichotomies. London: Sage Publications, 1998

[37] Wasko, M.M. and S. Faraj, Why Should I Share? Examining Social Capital and Knowledge Contribution in Electronic Networks of Practice. MIS Quarterly, 29(1): p. 35-57, 2005.

[38] Wellman, B., Networks in the global village: life in contemporary communities, Boulder Colo: Westview Press, 1998.

[39] Williams, R.L. and J. Cothrel, Four Smart Ways to Run Online Communites. Sloan Management Review, 41(1): p. 81-92, 2000 